\title{
Study on contact fatigue of a wind turbine gear pair considering surface roughness
}

\author{
Heli LIU ${ }^{1}$, Huaiju LIU ${ }^{1, *}$, Caichao $\mathrm{ZHU}^{1}$, Zhangdong SUN ${ }^{2}$, Houyi BAI ${ }^{3}$ \\ ${ }^{1}$ State Key Laboratory of Mechanical Transmissions, Chongqing University, Chongqing 400030, China \\ ${ }^{2}$ Hubei University of Automotive Technology, Shiyan 442002, Hubei, China \\ ${ }^{3}$ Chongqing Wangjiang Industrial Co., Chongqing, 400071, China \\ Received: 06 August 2018 / Revised: 19 December 2018 / Accepted: 10 January 2019 \\ (C) The author(s) 2019.
}

\begin{abstract}
Contact fatigue issues become more and more crucial in gear industry as they significantly affect the reliability and service life of associated mechanical systems such as wind turbine gearboxes. The contact fatigue behavior is mostly determined by the mechanical properties of materials and stress fields near the contact area, which is further influenced by the lubrication and surface roughness due to pressure fluctuations. In this study, a numerical model incorporating the lubrication state, tooth surface roughness, residual stress, and mechanical properties of the material is developed to determine the contact fatigue behavior of a megawatt level wind turbine carburized gear. The variations of the hardness and residual stress along the depth were characterized by the Vickers hardness measurement and X-ray diffraction test, respectively. The elastohydrodynamic lubrication theory was applied to predict the contact pressure distribution, highlighting the influence of the surface roughness that stemed from the original measurement through an optical profiler. The stress histories of the studied material points during a complete contact loading cycle were fast calculated using the discreteconcrete fast Fourier transformation (DC-FFT) method. Modified Dang Van diagrams under different working conditions were determined to estimate the contact fatigue failure risk. The effect of the root mean square (RMS) value of the surface roughness on the failure risk at critical material points were discussed in detail. Results revealed that the surface roughness significantly increases the contact fatigue failure risk within a shallow area, and the maximum risk appears near the surface.
\end{abstract}

Keywords: carburized gear; contact fatigue; surface roughness; residual stress; Dang Van criterion

\section{Introduction}

Due to the increasing demand for improved performance, reduced weight, and increased service lives of advanced geared machines such as wind turbines, which present significant contact fatigue issues leading to economic repercussions, diverse engineering techniques have been applied such as case carburizing [1], nitriding [2], and coating [3] to improve the resistance of gear contact fatigue failure. Gears failure due to rolling contact fatigue (RCF) occur in a variety of modes such as spalling [4], micropitting [5], and tooth flank fracture [6]. Gear contact fatigue is affected by various factors, including the lubrication state, tooth surface roughness, hardness gradient, and residual stress distribution, which cause the mechanism of gear contact fatigue failure to be unclear.

The impact of the lubrication and surface roughness on the tribological performance and fatigue behavior of contacting elements have been widely investigated in recent years, and significant improvements have been developed [7-9]. Qiao et al. [10] compared fatigue model results for elastohydrodynamic lubrication (EHL) with surface roughness. This study reported several

* Corresponding author: Huaiju LIU, E-mail: huaijuliu@cqu.edu.cn 


\begin{tabular}{|c|c|c|c|}
\hline \multicolumn{4}{|c|}{ Nomenclature } \\
\hline$B_{1}, B_{2}$ & $\begin{array}{l}\text { Gear tooth width of the driving and } \\
\text { driven gears, } m\end{array}$ & $\begin{array}{l}T_{1} \\
u_{\mathrm{r}}\end{array}$ & $\begin{array}{l}\text { Input torque of the driving gear, } \mathrm{N} \cdot \mathrm{m} \\
\text { Rolling velocity, } \mathrm{m} / \mathrm{s}\end{array}$ \\
\hline $\begin{array}{l}b_{\mathrm{H}} \\
c^{*}\end{array}$ & $\begin{array}{l}\text { Half Hertzian contact width, } \mathrm{mm} \\
\text { Tip clearance coefficient }\end{array}$ & $x_{1}, x_{2}$ & $\begin{array}{l}\text { Shifting coefficients of the driving and } \\
\text { driven gears }\end{array}$ \\
\hline E & $\begin{array}{l}\text { Young's modulus of the driving and } \\
\text { driven gears, } \mathrm{Pa}\end{array}$ & $Z_{1}, Z_{2}$ & $\begin{array}{l}\text { Number of teeth of the driving and } \\
\text { driven gears }\end{array}$ \\
\hline$E_{\mathrm{e}}$ & Equivalent Young's modulus, Pa & $\alpha$ & Pressure-viscosity efficient of the lubricant, \\
\hline ECD & Effective case depth, mm & & $\mathrm{Pa}^{-1}$ \\
\hline EHL & Elastohydrodynamic lubrication & $\alpha_{0}$ & Pressure angle of the gear, $\left(^{\circ}\right)$ \\
\hline$F$ & Tooth surface normal load, N/m & $\alpha_{\mathrm{D}}$ & Material parameter used in Dang Van criteria \\
\hline $\mathrm{HV}$ & Vickers hardness, HV & $\alpha_{\mathrm{t}}$ & Transverse pressure angle of the gear, $\left({ }^{\circ}\right)$ \\
\hline$m_{0}$ & Normal module of the gear pair, $\mathrm{m}$ & $\beta_{0}$ & Helix angle of the gear, $\left(^{\circ}\right)$ \\
\hline$N_{1}$ & Input speed of the driving gear, $\mathrm{r} / \mathrm{min}$ & $\sigma_{\mathrm{H}}$ & Hydrostatic stress, $\mathrm{Pa}$ \\
\hline $\begin{array}{l}p_{\mathrm{H}} \\
R\end{array}$ & $\begin{array}{l}\text { Maximum Hertzian contact pressure, } \mathrm{Pa} \\
\text { Failure risk of the gear contact fatigue }\end{array}$ & $\sigma_{-1}, \tau_{-1}$ & $\begin{array}{l}\text { Fully reversed bending and torsion } \\
\text { fatigue limits, } \mathrm{MPa}\end{array}$ \\
\hline$R_{1}, R_{2}$ & $\begin{array}{l}\text { Radius of curvature of the driving and } \\
\text { driven gears, } m\end{array}$ & $\begin{array}{l}\tau_{0} \\
\tau_{\text {Dang Van }}\end{array}$ & $\begin{array}{l}\text { Eyring characteristic stress, } \mathrm{MPa} \\
\text { Dang Van equivalent stress, } \mathrm{MPa}\end{array}$ \\
\hline$R_{\mathrm{e}}$ & Equivalent radius of curvature, $\mathrm{m}$ & $\tau_{\max }$ & Maximum shear stress, $\mathrm{MPa}$ \\
\hline RCF & Rolling contact fatigue & $\rho_{0}$ & Ambient oil density, $\mathrm{kg} / \mathrm{m}^{3}$ \\
\hline RMS & Root mean square, $\mu \mathrm{m}$ & $\eta_{0}$ & Oil viscosity at ambient pressure, $\mathrm{Pa} \cdot \mathrm{s}$ \\
\hline$t_{\text {contact }}$ & Gear contact time, $\mathrm{s}$ & $v$ & Poisson's ratio of materials \\
\hline
\end{tabular}

multiaxial fatigue criteria such as Findley and Dang Van criteria which were applied to represent the multiaxial stress state and subsequently, to predict the fatigue failure probability. Moreover, according to Liu et al. [11], a thermal starved EHL line contact model for a spur gear pair was derived to study the effect of the working conditions under the starved lubrication, addressing the importance of good lubrication on a gear surface initiated failure resistance. $\mathrm{Pu}$ et al. [12] evaluated the contact fatigue performance under combined rolling and sliding motions by considering the sinusoidal roughness. The results imply that sliding could reduce the contact fatigue life dramatically, and rough surface contacts would lead to accelerated pitting failures. Yan et al. [13] numerically analyzed the lubrication characteristics and fatigue life under full film and surface topography. Zhu et al. [14] studied the effect of rough surface topography on mixed lubrication characteristics. Results reveal that under the mixed EHL state, maximum pressure, contact load ratio, friction, flash temperature, and maximum subsurface shear stress increased dramatically as the roughness increased. Zhou et al. [15] discussed the relationship between microstructure characterization parameters and contact characteristic parameters of two cylinders with surface roughness. Due to the development of the industrial manufacturing technologies, the root mean square (RMS) of the gear surface roughness could be controlled at a relatively low value. For instance, the RMS of a wind turbine gear can be controlled at approximately $0.50 \mu \mathrm{m}$ by applying manufacturing processes. Although the gear lubrication is sometimes guaranteed, micropitting can still be observed due to the significant influence of the surface roughness. Sheng and Kahraman [16] proposed a numerical model considering the lubrication and surface topography to predict the gear micropitting life, while the residual stress, the material properties, etc., were not considered. Cardoso et al. [17] estimated the gear micropitting performances of high pressure nitriding steel gears which were lubricated with a standard mineral lubricant and two biodegradable 
esters. Experimental results showed that the gears with the ester lubricants presented better micropitting performance than the gears with the mineral oil. Despite numerous theoretical and experimental investigations, the micropitting mechanism has still not been fully determined and requires further study.

As revealed by the experimental observations in Ref. [18], the fatigue crack mostly initiates within the contact stressed zone, where the mechanical properties and residual stress highly vary. This implies that the fatigue damage is sensitive to those variations [19]. In addition, a large amount of residual stresses can also be introduced through the machining, heat treatment, or surface treatment processes, which need to be considered. Walvekar et al. [20] studied the RCF lives of case carburized steels and calculated the damage parameters. The effect of the residual stress distribution on the RCF lives was also investigated. Rudenko and Val'ko [21] studied the contact fatigue resistance of carburized gears experimentally, and an expression for the ultimate deep contact fatigue resistance of carburized gears was derived. Lv et al. [22] studied the effect of the microshot peened treatment on the fatigue behavior of gears as well as the effects of the relaxation mechanism of the compressive residual stress on the gear fatigue performance. Inoue and Kato [23] proposed an experimental formula for the estimation of the bending fatigue strength of carburized gears. This formula also presents a way of enhancing gear fatigue strength by increasing the surface hardness and residual stress. MackAldener and Olsson [24] analyzed a gear failure mode called tooth interior fatigue fracture by numerical simulations using Finite element model (FEM) and the critical plane fatigue initiation criterion according to Findley, highlighting the effect of the residual stress. Brandão et al. [25] proposed a micropitting test performed with spur gears considering the residual stress on a Forschungsstelle für Zahnräder und Getriebebau (FZG) test machine to predict the surface damage.

However, these studies do not simultaneously consider the hardness gradient, residual stress gradient, lubrication state, and surface roughness in the prediction of the gear contact fatigue. A more comprehensive numerical model needs to be developed to include complicated contact situations. Herein, a numerical model incorporating the variations of the hardness and the residual stress is proposed to describe the stress responses and to estimate the contact fatigue performance of a carburized gear under the lubrication condition. Based on the numerical results, the influence of the RMS value of the surface roughness on the gear contact fatigue is discussed in detail.

\section{Simulation methodology}

A numerical model for the prediction of the contact fatigue performance of a carburized gear is described in detail as follows. Under a given loading and lubrication condition and different surface topographies, the gear contact fatigue risk can be estimated based on the fast-calculated stress histories and modified Dang Van diagram. Moreover, the material properties and residual stress distribution are considered for a more comprehensive analysis. The technical process of this study is displayed in Fig. 1. The model primarily consists of four aspects: gear contact parameters, lubrication model, Dang Van diagram, and explanation of failure risk index.

\subsection{Gear contact parameters}

The gear sample studied in this work arises from the intermediate parallel stage of a $2 \mathrm{MW}$ wind turbine gearbox. Such a gear stress concentration becomes more pronounced when the gear engages at the pitch point compared with the other meshing positions [26], thus the contact fatigue failure is primarily evaluated at this critical position. The gear contact at the pitch point can be equivalent to two deformable circles with different radii of curvature $\left(R_{1}, R_{2}\right)$ contacting

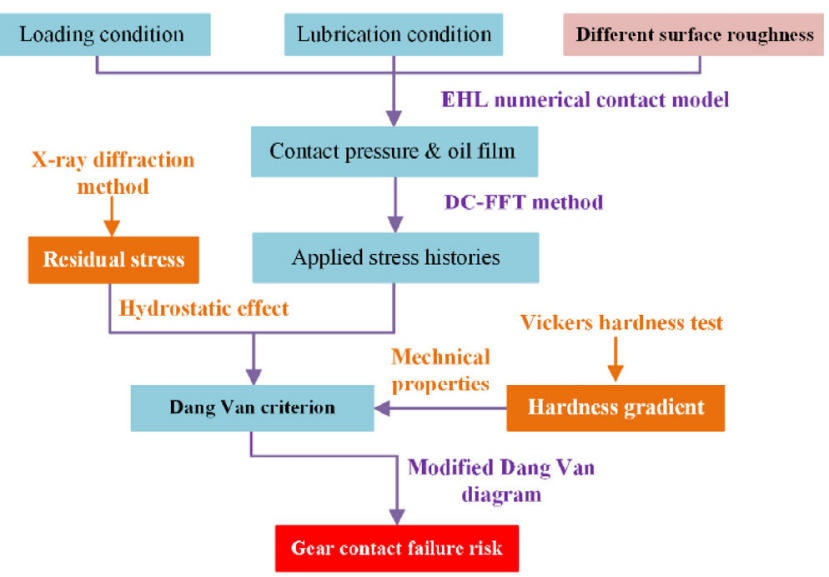

Fig. 1 Overall technical process of the study. 
with each other. Subsequently, this model can be further simplified as a rigid circle with an equivalent radius of curvature $\left(R_{\mathrm{e}}\right)$ contacting with an infinite elastic half-space, with an equivalent Young's modulus $\left(E_{\mathrm{e}}\right)[27,28]$. The schematic diagram of the gear contact model based on the plane strain assumption is illustrated in Fig. 2, as well as the information on the coordinate system. The $x$ coordinate denotes the rolling direction, the $z$ coordinate represents the direction of the depth, and the $y$ coordinate represents for the gear width direction. The model geometric as well as the operating parameters are listed in Table 1. The gear manufacturing process is also illustrated in Table 1 due to its crucial role on the final fatigue performance of gears. In fact, the heating treatment process was performed at a carburizing temperature of $930{ }^{\circ} \mathrm{C}$, intensive carburization potential (26-30 h) of $1.03 \%-1.13 \%$, diffusion potential $(14-24 \mathrm{~h})$ of

Table 1 Gear parameters and manufacturing process. Main manufacturing process: carburizing, quenching, tempering, and grinding.

\begin{tabular}{cc}
\hline \multicolumn{2}{c}{ Main gear parameter } \\
\hline Teeth number & $Z_{1}=121, Z_{2}=24$ \\
Normal module & $m_{0}=0.011 \mathrm{~m}$ \\
Pressure angle & $\alpha_{0}=20^{\circ}$ \\
Helix angle & $\beta_{0}=12^{\circ}$ \\
Gear tooth width & $B_{1}=0.295 \mathrm{~m}, B_{2}=0.3 \mathrm{~m}$ \\
Shifting coefficient & $x_{1}=0.034, x_{2}=0.4$ \\
Transverse pressure angle & $\alpha_{t}=20.41^{\circ}$ \\
Tip clearance coefficient & $c^{*}=0.4$ \\
Poisson's ratio & $v=0.3$ \\
Young's modulus & $E=2.10 \times 10^{11} \mathrm{~Pa}$ \\
Input torque & $T_{1}=282,768 \mathrm{~N} \cdot \mathrm{m}$ \\
Input speed & $N_{1}=77 \mathrm{r} / \mathrm{min}$ \\
\hline
\end{tabular}

$0.65 \%-0.80 \%$, high-temperature tempering (4-8 h) of $670{ }^{\circ} \mathrm{C}$, quenching $(6-12 \mathrm{~h})$ of $820^{\circ} \mathrm{C}$, and a tempering (12-24 h) of $170-200{ }^{\circ} \mathrm{C}$. Subsequently, the gear flank is ground for the final surface geometry.

The tooth surface roughness, due to its notable influence on the pressure fluctuation, is considered in the proposed model. The deterministic nature of the model allows the explicit description of the surface roughness. The gear surface roughness, processed by the generating grinding method, is measured using the optical device Alicona G4 equipped with highresolution lenses. Figure 3 shows the gear surface topography and processed data used in the calculation. The RMS value of the measured roughness is $0.25 \mu \mathrm{m}$, and the gap along the rolling direction between two adjacent points is $0.18 \mu \mathrm{m}$.

\subsection{Lubrication model}

Following the developments of the EHL and microEHL theories, gear lubrication has been extensively studied in recent years and relevant numerical models have been developed [29, 30]. For clarity, essential equations are explained here. For the plane strain assumption, the fluid flow in the contact area is expressed by a one-dimensional generalized Reynolds equation [31]:

$$
\frac{\partial}{\partial x}\left(\frac{\rho h_{\mathrm{e}}^{3}}{\eta^{*}} \frac{\partial p}{\partial x}\right)=12 u_{\mathrm{r}} \frac{\partial\left(\rho h_{\mathrm{e}}\right)}{\partial x}+12 \frac{\partial\left(\rho h_{\mathrm{e}}\right)}{\partial t}
$$

where $p, h_{\mathrm{e}}$, and $\rho$ represent the fluid pressure, film thickness, and lubricant density, respectively. The rolling velocity is represented by $u_{r}=\left(u_{1}+u_{2}\right) / 2$, where $u_{i}(i=1,2)$ is the current rolling velocity of the

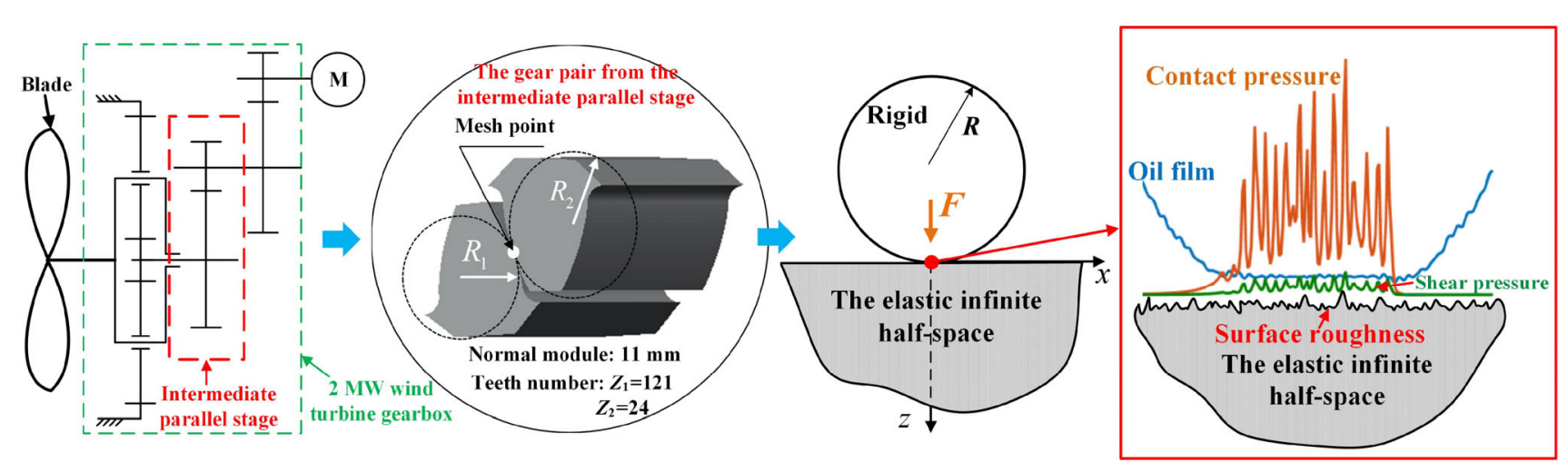

Fig. 2 Gear contact model. 

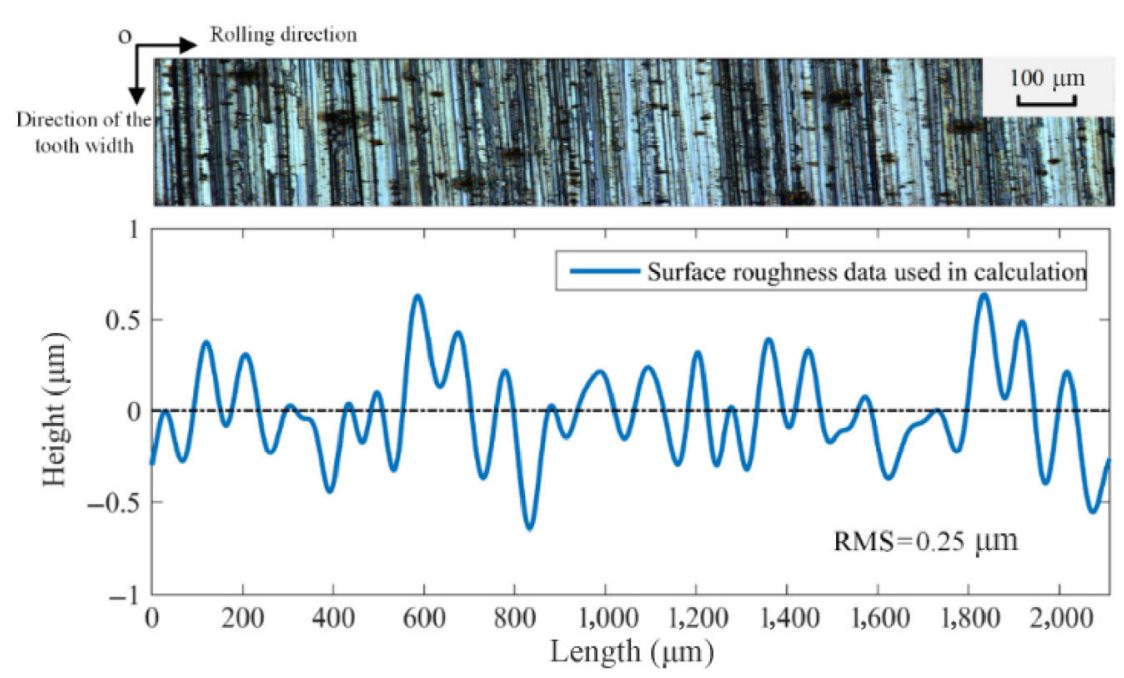

Fig. 3 Gear surface texture and the transformed surface roughness data.

driving and driven gears, respectively. The variation of the lubricant density depends on the pressure which can be derived through the Dowson-Higginson equation [32]:

$$
\rho=\rho_{0}\left(1+\frac{0.6 \times 10^{-9} p}{1+1.7 \times 10^{-9} p}\right)
$$

where $\rho_{0}$ is the ambient oil density. An effective viscosity $\eta^{*}$ is introduced to characterize the nonNewtonian behavior, which is expressed as the ReeEyring fluid. The equivalent viscosity of the Ree-Eyring fluid is expressed as follows:

$$
\eta^{*}=\eta \frac{\tau}{\tau_{0}} / \sin h\left(\frac{\tau}{\tau_{0}}\right)
$$

where $\tau_{0}$ is the Eyring characteristic stress and is set to $10 \mathrm{MPa}$ in the present work. $\tau$ is the current oil shear stress, and $\eta$ is the viscosity as a function of the pressure [33]:

$$
\eta=\eta_{0} \exp \left\{\left(\ln \eta_{0}+9.67\right)\left[-1+\left(1+p p_{0}\right)^{z_{\mathrm{e}}}\right]\right\}
$$

where $p_{0}$ is the pressure index $p_{0}=5.1 \times 10^{-9}, \eta_{0}$ is the oil viscosity at ambient pressure, and $z_{\mathrm{e}}$ is fixed as a constant of 0.60 .

The oil film thickness $h$, considering the term of the surface roughness, can be calculated as follows:

$$
h(x, t)=h_{0}(t)+\frac{x^{2}}{2 R}+E D(x, t)+S R(x, t)
$$

where $h_{0}$ is the initial separation between two interacting surfaces, $R$ is the equivalent radius of curvature, $E D$ is the elastic deformation, and $S R$ denotes the term of the surface roughness. Moreover, the lubrication parameters are listed in Table 2. The previous equations are dimensionless based upon the Hertzian parameters, namely the half-Hertzian contact width $b_{\mathrm{H}}$ and maximum Hertzian pressure $p_{\mathrm{H}}$ [27]. The discrete convolute, i.e., the fast Fourier transformation (DC-FFT) method, first proposed by Liu et al. [34], is adopted for the fast calculation of the elastic deformation and stress components. Herein, the friction coefficient is assumed to be 0.10 . A more detailed explanation on the solving strategy is detailed in Ref. [11].

As shown in Fig. 4, the calculation domain of the material points covers a range of $-4.0 b_{\mathrm{H}} \leq x \leq 0$, $0 \leq z \leq 4.0 b_{\mathrm{H}}$, which is divided into $N_{x} \times N_{z}=64 \times 400$ equally spaced grids. The time of the gear contact should be guaranteed to keep each individual point completing an entire loading cycle and is estimated as follows [35]:

$$
t_{\text {contact }}=4.0 b_{\mathrm{H}} / u_{\mathrm{r}}
$$

Table 2 Lubrication parameters.

\begin{tabular}{cc}
\hline Parameter & Value \\
\hline Eyring characteristic stress & $\tau_{0}=10 \mathrm{MPa}$ \\
Oil viscosity at ambient pressure & $\eta_{0}=0.04 \mathrm{~Pa} \cdot \mathrm{s}$ \\
Ambient oil density & $\rho_{0}=870 \mathrm{~kg} / \mathrm{m}^{3}$ \\
Pressure-viscosity efficient & $\alpha=2.2 \times 10^{-8} \mathrm{~Pa}^{-1}$ \\
\hline
\end{tabular}




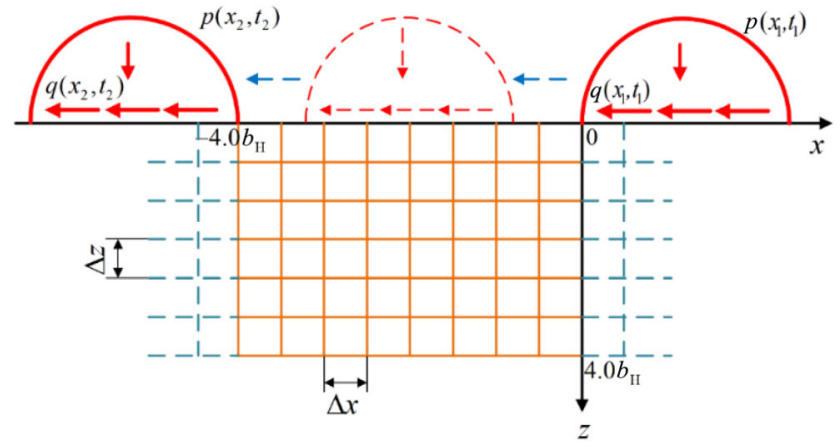

Fig. 4 Schematic diagram of the calculation domain.

where $b_{\mathrm{H}}$ is $0.86 \mathrm{~mm}$, and $u_{\mathrm{r}}$ is $2.04 \mathrm{~m} / \mathrm{s}$ at the pitch point in the calculation. Therefore, the gear contact time can simply be calculated as $0.0017 \mathrm{~s}$. The distance between two adjacent measured data points is approximately $0.18 \mu \mathrm{m}$ along the rolling direction. Compared with the distance between two adjacent interested material points within the calculation domain (approximately $54 \mu \mathrm{m}$ ), the amount of the measured surface roughness data points is large enough to obtain high accuracy and efficiency.

\subsection{Dang Van diagram}

According to the complicated multiaxial stress states during the gear contact period, various multiaxial fatigue criteria have been applied in gear contact fatigue studies. Among them, the Dang Van multiaxial fatigue criterion is widely applied to evaluate the contact fatigue performance $[36,37]$. The significant hydrostatic stress distribution caused by cyclic contact, which is absent in classical fatigue situations, could be explicitly considered in this criterion. The Dang Van equivalent stress $\tau_{\text {DangVan }}$ is defined as a linear function of the maximum shear stress $\tau_{\max }$ and the hydrostatic stress $\sigma_{\mathrm{H}}$ :

$$
\tau_{\text {DangVan }}(t)=\tau_{\max }(t)+\alpha_{\mathrm{D}} \cdot \sigma_{\mathrm{H}}(t)
$$

where $\alpha_{\mathrm{D}}$ is a material parameter which could be evaluated according to the following equation [38]:

$$
\alpha_{\mathrm{D}}=\frac{3 \tau_{-1}}{\sigma_{-1}}-\frac{3}{2}
$$

where $\sigma_{-1}$ and $\tau_{-1}$ are the fully reversed bending fatigue limit and fully reversed torsion fatigue limit of the material points, respectively, which depend on the depth location. Figure 5 presents the original Dang Van diagram representing the contact fatigue limit [39]. In this diagram, the $x$ coordinate denotes the hydrostatic stress, and the $y$ coordinate represents the maximum shear stress $\tau_{\max }$. The original Dang Van curve is characterized as an inclined line with a negative slope $\alpha_{\mathrm{D}}$. For any load path data on or above this Dang Van curve, the fatigue crack initiation occurrence is expected [39, 40], and thus the corresponding material points should be highly noticed.

The original Dang Van criterion predicts a detrimental effect of tensile hydrostatic, and an overestimated positive influence is expected from compressive values [41]. Desimone et al. [40] reported an over-optimistic prediction of the effect of the compressive residual stress on the RCF issues, especially when the compressive hydrostatic stress exists during contact. Therefore, when the value of the hydrostatic stress is negative (the negative part of the $x$ coordinate), the original inclined Dang Van curve should be modified by evaluating the RCF failure.

The residual stress plays a non-negligible role, together with the applied stress, on the formation of the final stress field. The residual stress gradient of the rolling direction was characterized by applying a X-ray diffraction test [26]. The electro-polishing is used for the measurement of the residual stress gradient distribution. The profile is assumed to remain negative along the direction of depth, representing the compressive residual stress state. Several groups of gear samples are tested, and based on the measured data and the deviation, the residual stress is comprised in a range of approximately $40 \mathrm{MPa}$, which may be

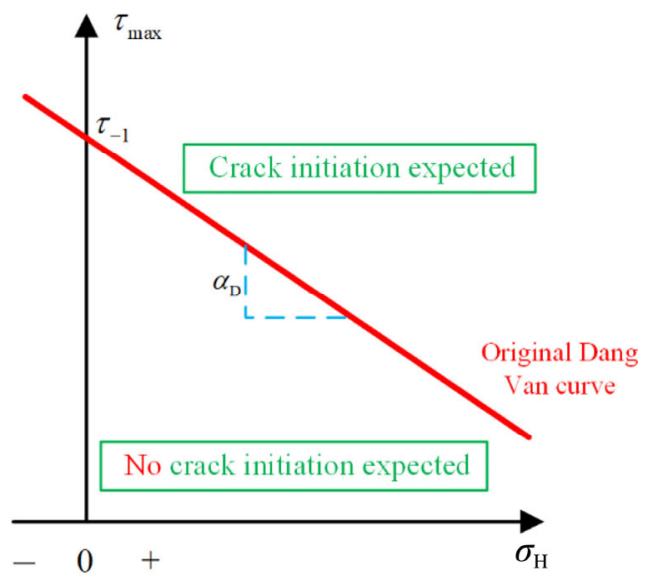

Fig. 5 Original Dang Van diagram. 
caused by the stress relaxation or the uneven measured tooth surface. As the residual stress along the $z$ coordinate is much smaller than that in the other two directions, only the residual stresses along the rolling direction $\sigma_{\mathrm{r}, x}$ and width direction $\sigma_{\mathrm{r}, y}$ are superposed to the corresponding stress components $\sigma_{x}$ and $\sigma_{y}$ linearly for the further calculation, and $\sigma_{\mathrm{r}, x^{\prime}}$ $\sigma_{\mathrm{r}, y}$ profiles along the depth are assumed to have same profiles along the depth [42].

Considering residual stress into account, the Dang Van equivalent stress could be formulated as follows [43]:

$$
\tau_{\text {DangVan }}(t)=\tau_{\max }(t)+\alpha_{\mathrm{D}}\left[\sigma_{\mathrm{H}, \text { load }}(t)+\sigma_{\mathrm{H}, \text { residual }}(t)\right]
$$

where the $\alpha_{\mathrm{D}} \cdot \sigma_{\mathrm{H} \text {, load }}$ is modified by the superimposition of the residual stress distribution through the hydrostatic part of the residual stress tensor $\sigma_{\mathrm{H} \text {, residual }}$ [41]. Hence a different Dang Van safe locus is proposed and can be identified in two straight line segments. One is horizontal, representing a conservative fatigue limit for the region of compressive hydrostatic stress values, and the other presents a negative slope $\alpha_{\mathrm{D}}$, as illustrated in Fig. 6 [41]. The modified multiaxial

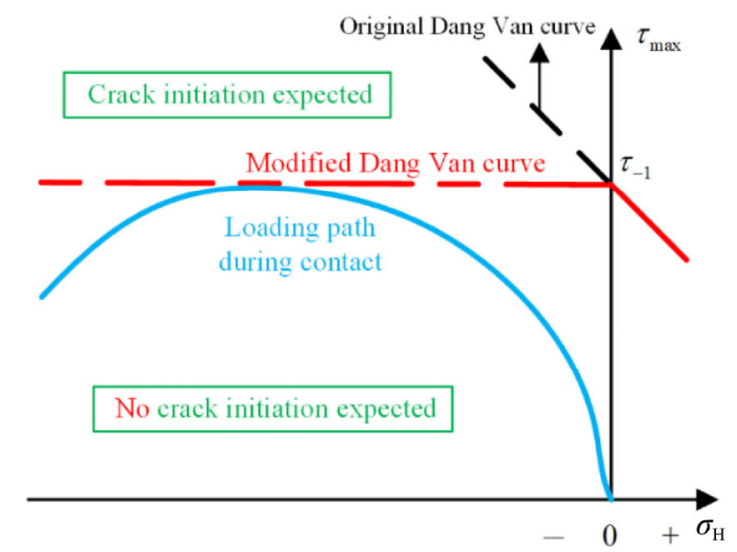

Fig. 6 Modified Dang Van diagram. fatigue limit does not depend on the variation of the amplitude of the compressive hydrostatic stress, indicating that the over-optimistic positive effect of the compressive hydrostatic stress on the contact fatigue problems is modified. Moreover, based on the RCF experiment in Ref. [44], the conservative horizontal locus shows a more accurate fit than the original Dang Van curve for the compressive hydrostatic stress.

\subsection{Index of failure risk}

According to the characteristics of heat treatment and carburizing, the hardness value decreases gradually from the surface to the core substrate within the hardened layer of a carburized gear. The hardness gradient variations would cause changes in the local material strength, fully-reversed bending limit, and torsion fatigue limit. Therefore, the gradient properties must be considered when analyzing carburized gear contact fatigue issues. Figure 7 shows the measured hardness data using the Vickers indentation test machine, and the measured data is curve-fitted by the third order Fourier series analysis. In order to avoid the possible excessive indentation, a test force of $4.9 \mathrm{~N}$ is chosen. Each measurement point along the tooth flank is measured five times and finally, the average hardness value is determined. As observed in Fig. 7, the hardness varies from 650 to $450 \mathrm{HV}$, from the case to the core. Moreover, the effective case depth (ECD), defined as the hardness value is $550 \mathrm{HV}$, is approximately $2.20 \mathrm{~mm}$. According to the measurement, the deviation of the measured hardness data is within $10 \mathrm{HV}$.

The values of the fully reversed bending fatigue limit $\sigma_{-1}$ and fully reversed torsion fatigue limit $\tau_{-1}$ used in the Dang Van criterion depend on the material depth and can be determined based on the hardness
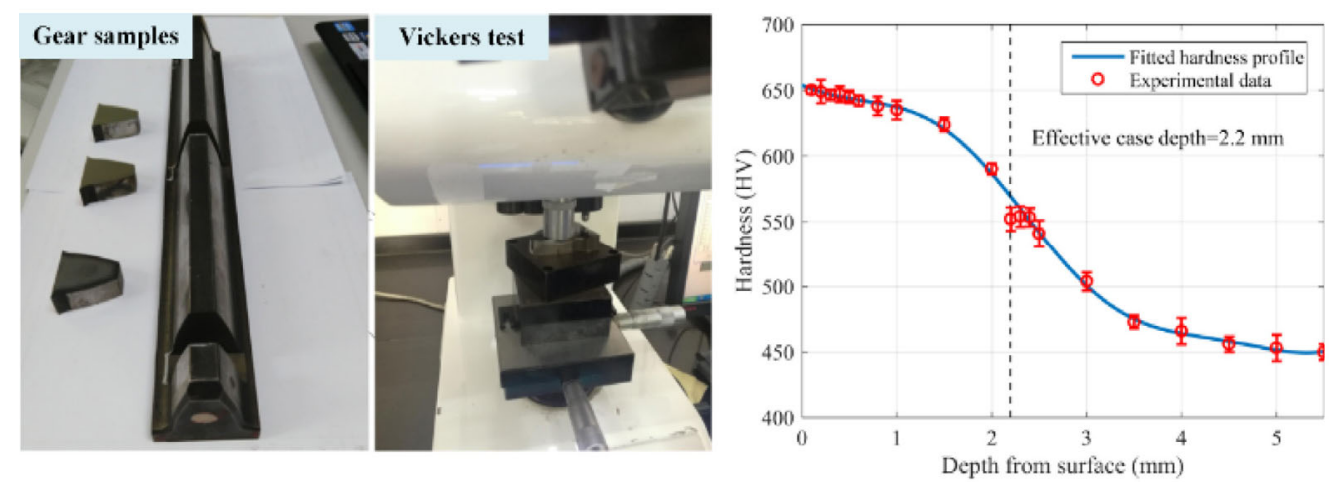

Fig. 7 Gear samples, measurement device, measured hardness data, and fitted profile. 
gradient by using the following equations [45]:

$$
\left\{\begin{array}{l}
\tau_{-1}(z)=0.773 \mathrm{HV}(z)-[\mathrm{HV}(z)]^{2} / 3170 \quad(\mathrm{MPa}) \\
\sigma_{-1}(z)=\tau_{-1}(z) / 0.577 \quad(\mathrm{MPa})
\end{array}\right.
$$

where $z$ represents the depth from the surface. Figure 8 shows the profiles of hardness, fatigue limits under fully reversed bending $\left(\sigma_{-1}\right)$, and torsion $\left(\tau_{-1}\right)$ along the direction of depth. The value of $\sigma_{-1}$ varies from $0.64 \mathrm{GPa}$ on the surface to $0.49 \mathrm{GPa}$ in the core. In addition, $\tau_{-1}$ has a similar profile as $\sigma_{-1}$ and varies from 0.37 to $0.28 \mathrm{GPa}$. The limit gradually decreases with the increase of the depth, and the load path of each material point should be compared with its corresponding limit in order to capture the severity of each instant in the contact period.

For the evaluation of contact fatigue of carburized gears, a concept called "the material exposure" (a ratio of the equivalent shear stress considering residual stress and local material strength derived from the hardness gradient) is described in Refs. [46, 47]. Accordingly, an index $R$ is defined to estimate the risk of

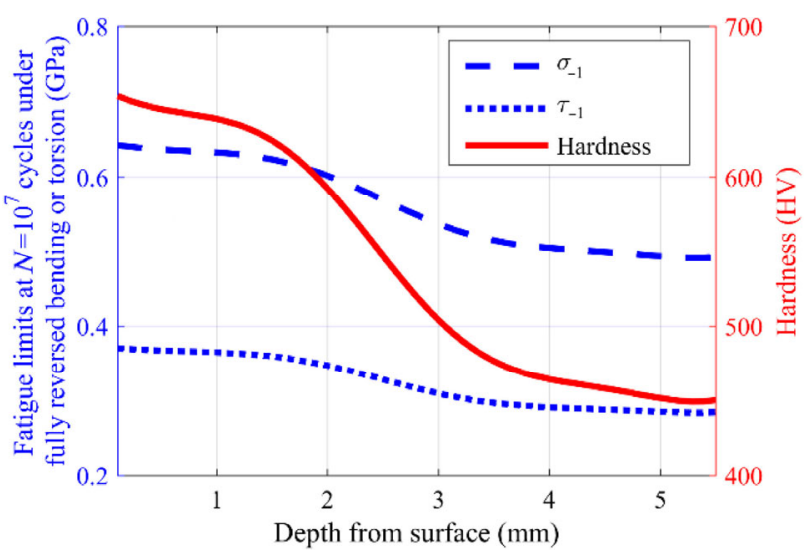

Fig. 8 Hardness profile, fatigue limit under fully reversed bending, and torsion.

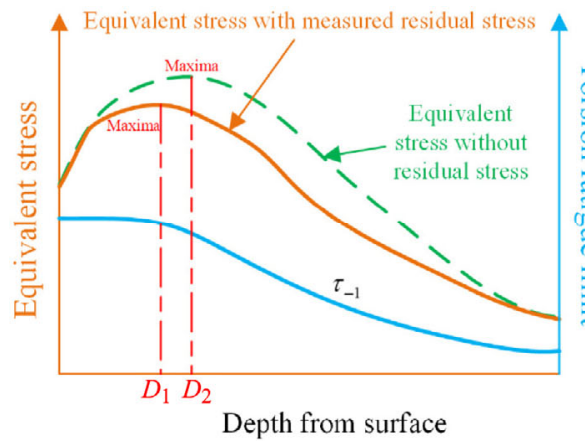

the gear contact fatigue along the depth as follows:

$$
R(z)=\frac{\tau_{\text {Dang Van }}(z)}{\tau_{-1}(z)}
$$

where $R$ is the risk of gear contact fatigue, $\tau_{\text {Dang Van }}$ is the Dang Van equivalent stress, $\tau_{-1}$ is the torsion fatigue limit mentioned previously, and $z$ represents the depth. Figure 9 shows the schematic diagram of the Dang Van equivalent stress $\tau_{\text {Dang Van }}$ with and without the measured residual stress and the resultant distribution of the fatigue failure risk. It can be observed that the equivalent stress is affected by the residual stress, which can further influence the fatigue failure risk.

\section{Results and discussions}

\subsection{Dang Van diagram with smooth surface}

The Dang Van equivalent stress history and the modified Dang Van diagrams can be evaluated to demonstrate the effect of the measured compressive residual stress on the stress distribution and gear contact fatigue performance. Figure 10 illustrates the Dang Van equivalent stress history of the middle point of the contact period for a smooth surface. The stress distribution of this specific point is representative of other material points because of the smooth surface. The measured compressive residual stress slightly decreases the maximum equivalent stress from 0.36 to $0.34 \mathrm{GPa}$. Moreover, the range of the maximum values becomes shallower because of such residual stress distribution.

Figures 11(a) and 11(b) present the stress evolution in the Dang Van diagram of the same material point with a smooth surface. According to the previous description, the $x$ coordinate represents the hydrostatic

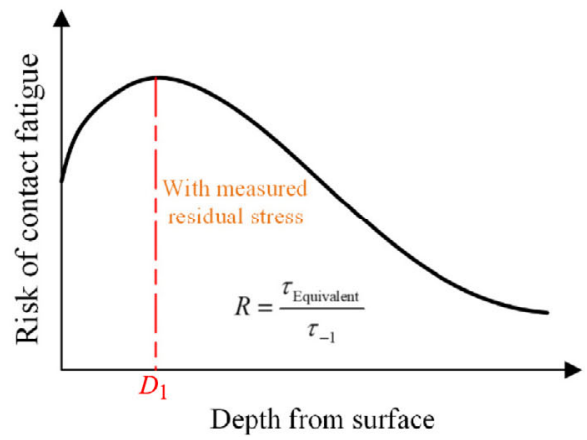

Fig. 9 Schematic diagrams of the equivalent stress and risk of gear contact fatigue. 

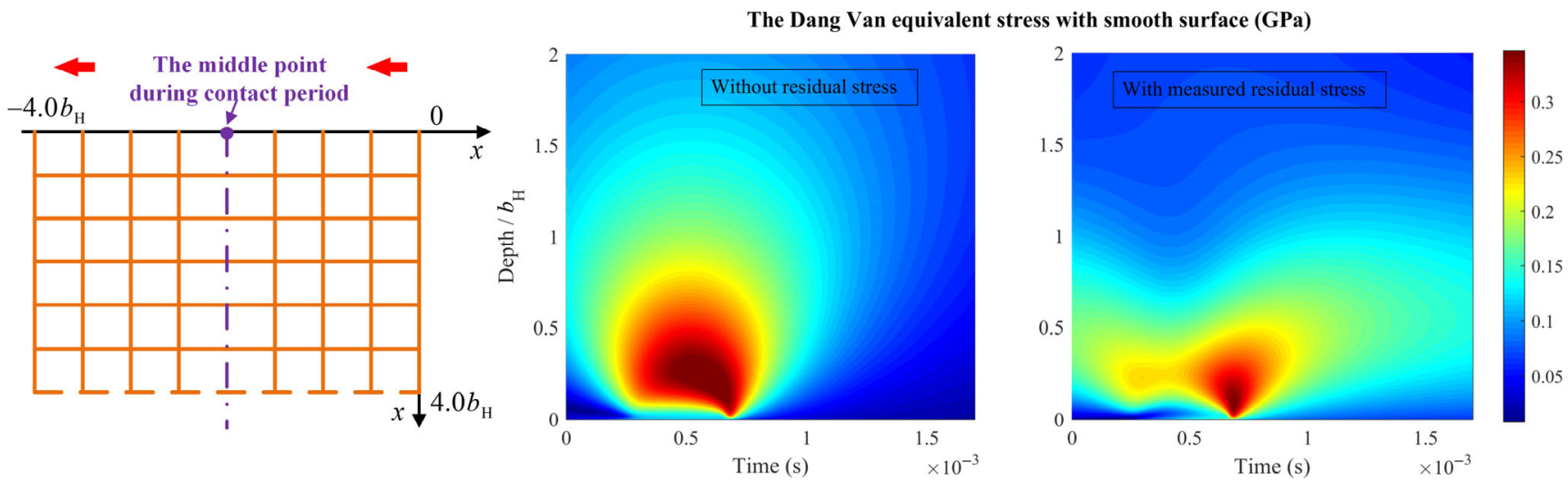

Fig. 10 Dang Van equivalent stress as a function of the time and depth for a smooth surface.

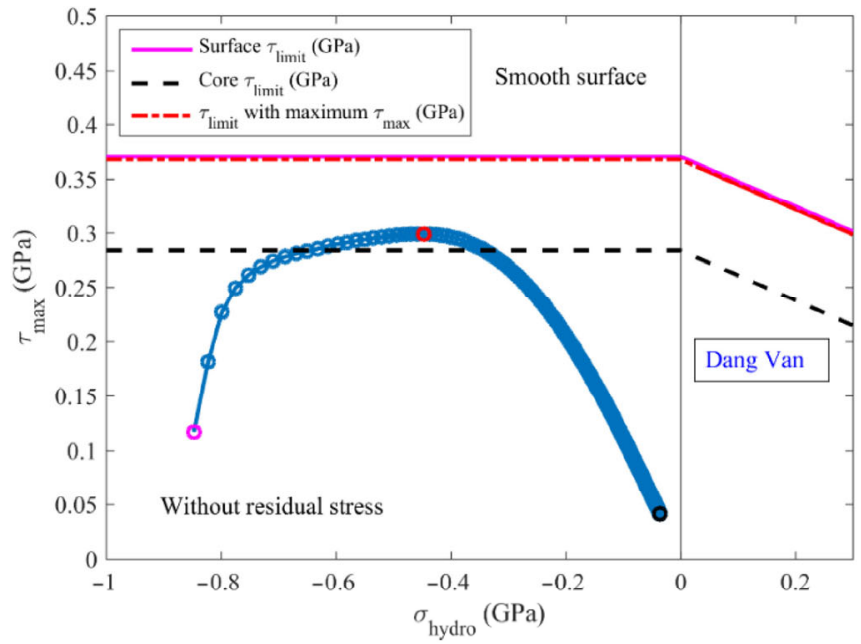

(a)

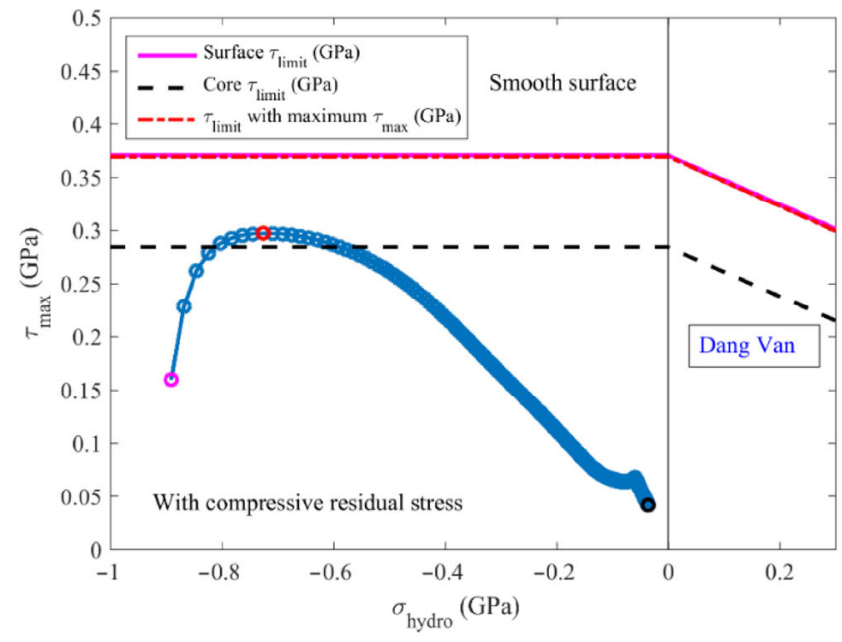

(b)

Fig. 11 Stresses evolution in the Dang Van diagram with (a) a smooth surface and without residual stress, and (b) with a smooth surface and compressive residual stress.

stress and the $y$ coordinate represents the maximum shear stress $\tau_{\max }$. The torsion fatigue limit line $\tau_{-1}$ at the gear surface and core, and the corresponding limit line of the maximum value of $\tau_{\max }$ are illustrated. The Dang Van equation is expressed as a line with a slope $\alpha_{\mathrm{D}}$ based on the depth mentioned previously. In this section, the data of 401 material points along a depth down to $4.0 b_{\mathrm{H}}$ at the middle of the contact length is studied.

Overall, the load path data of each material point does not reach its corresponding torsion fatigue limit, when the smooth surface is considered. This indicates that almost no contact fatigue issue is expected to occur under this circumstance. Considering the superposition of the residual stress distribution, the maximum shear stress $\tau_{\max }$ at the subsurface decreases, and the location of the maximum becomes closer to the surface. However, the maximum value of $\tau_{\max }$ almost remains unchanged. Such compressive residual stress is beneficial to the drop of the gear contact fatigue failure possibilities at the subsurface.

\subsection{Effect of surface roughness on the Dang Van diagrams}

Figures 12 (a) and 12(d) present the stress distributions at different depths during the contact process in the Dang Van diagrams with residual stress and different surface roughness (the smooth surface and RMS are $0.1,0.3,0.5 \mu \mathrm{m}$, respectively) in order to simulate the surface topography conditions of both ground gears and superfinished gears. The studied material points are chosen from depths of $0.01 b_{\mathrm{H}}, 0.02 b_{\mathrm{H}}, 0.5 b_{\mathrm{H}}$, 
$1.0 b_{\mathrm{H}}$, and $2.0 b_{\mathrm{H}}$, which have a peak maximum shear stress $\tau_{\max }$ during the contact period. Herein, 33 material points are studied for each depth during the same contact period along the rolling direction. The torsion fatigue limits vary at different depths because of the gradient properties, which indicates that the peak maximum shear stress $\tau_{\text {max }}$ should be compared with the corresponding fatigue limit at the same depth. It should be noticed that the torsion fatigue limits of the surface, at the depths of $0.01 b_{\mathrm{H}}$ and $0.02 b_{\mathrm{H}}$, almost coincide with each other.

As observed in Fig. 12(a), the stress distributions are all below the torsion fatigue line for each relative depth with a smooth surface. The load path for a given depth remains constant. Therefore, the crack initiation is not expected at any depth.

When RMS $=0.1 \mu \mathrm{m}$, as shown in Fig. 12(b), obvious discrepancies in the data can be observed at the depths of $0.01 b_{\mathrm{H}}$ and $0.02 b_{\mathrm{H}}$ due to the surface roughness. However, none of the torsion fatigue limits at each corresponding depth is exceeded.

As the RMS of the surface roughness increases to $0.3 \mu \mathrm{m}$ in Fig. 12(c), the data at the depths of $0.01 b_{\mathrm{H}}$ and $0.02 b_{\mathrm{H}}$ fluctuate more dramatically, and the influence of the surface roughness can be observed at deeper locations such as $0.5 b_{\mathrm{H}}$. At the depth of $0.01 b_{\mathrm{H}}$, which is close to the surface, approximately half of the points are above the corresponding limit line, and the maximum $\tau_{\max }$ exceeds $0.4 \mathrm{GPa}$. Moreover, several data points exceed the corresponding limit line at the depth of $0.02 b_{\mathrm{H}}$.

When RMS $=0.5 \mu \mathrm{m}$, as for the depth of $0.01 b_{\mathrm{H}}$, all studied points are over the corresponding limit line, as observed in Fig. 12(d). The maximum $\tau_{\max }$ is approximately $0.6 \mathrm{GPa}$. Moreover, the maximum $\tau_{\max }$ of $0.02 b_{\mathrm{H}}$ is $0.55 \mathrm{GPa}$, which is remarkably greater

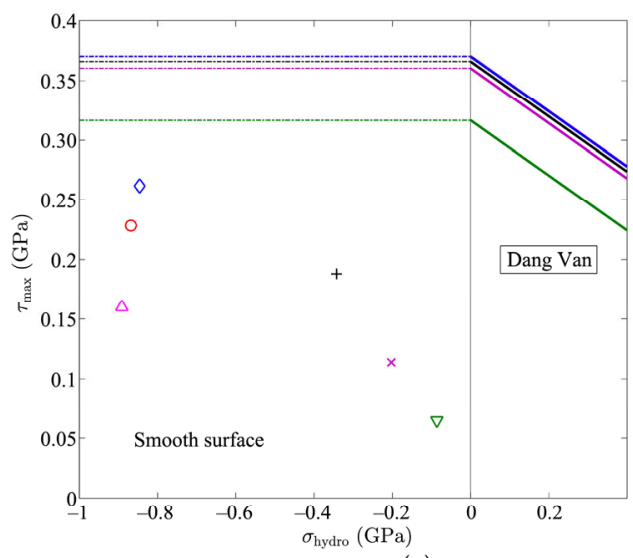

(a)

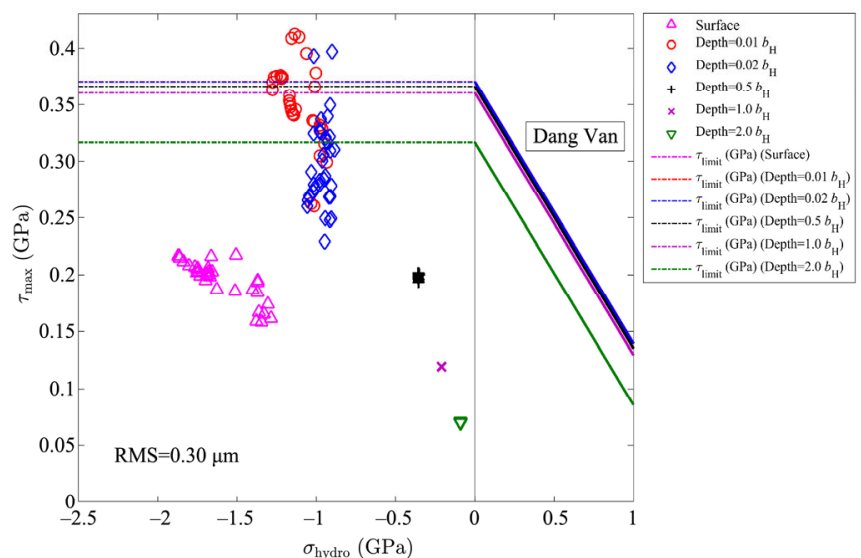

(c)

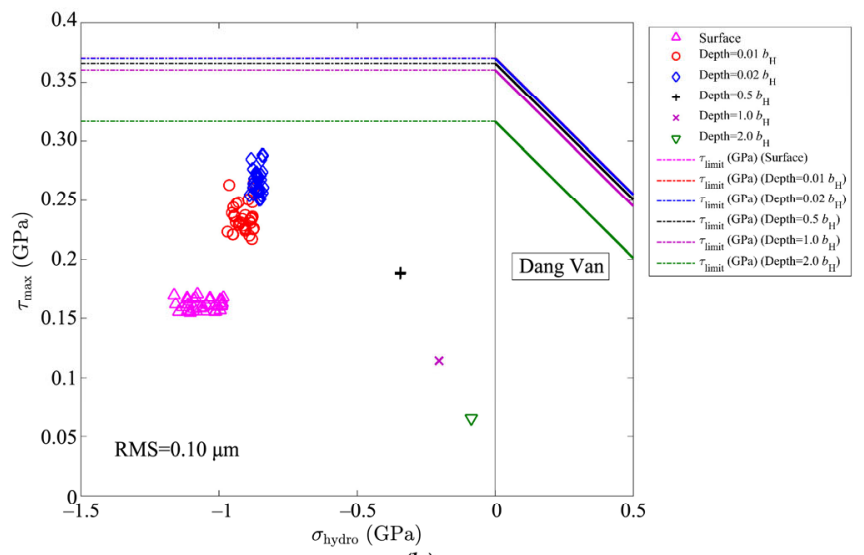

(b)

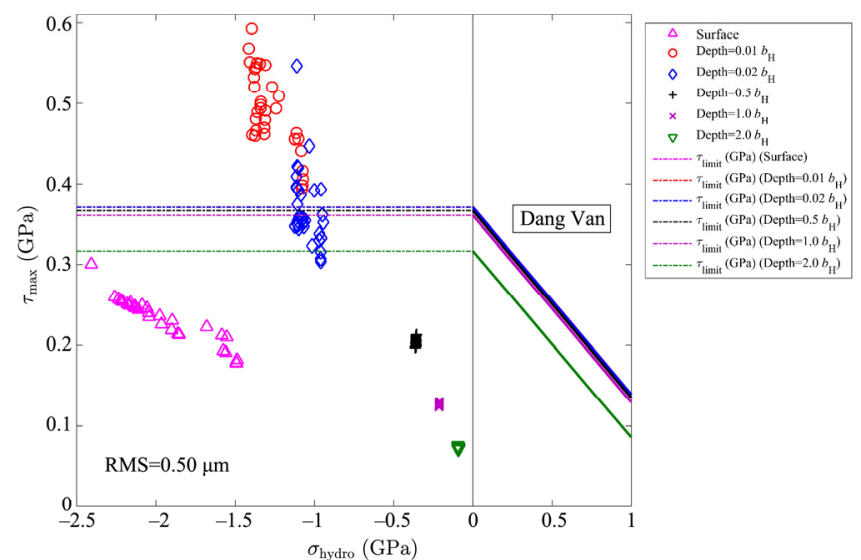

(d)

Fig. 12 Stresses distributions in the Dang Van diagram at different depths (a) with a smooth surface, (b-d) when the surface roughness $\mathrm{RMS}=0.1,0.3$, and $0.5 \mu \mathrm{m}$, respectively. 
than its corresponding limit value $\tau_{-1}$. None of the data point at the surface exceeds the corresponding limit line, but the variation of the hydrostatic stress $\sigma_{\mathrm{H}}$ distribution at the surface fluctuates within a wide range because of the fluctuation of the surface pressure due to the roughness.

It can be summarized that the influence of the surface roughness is more significant as the RMS increases, especially at the near surface where the stress distributions highly fluctuate. The near surface could be regarded as the expected crack initiation positions rather than the surface, although the important fluctuation of $\sigma_{\mathrm{H}}$ could be found at the surface. However, the effects of the surface roughness on the stress distribution drop sharply as the depth becomes deeper.

\subsection{Effect of surface roughness on the risk of contact fatigue}

In order to investigate the gear contact failure probability influence range of the surface roughness, the risk of the gear contact fatigue along the depth with different surface asperities is evaluated according to Section 2.4. Figure 13 schematically illustrates the risk of the contact fatigue along the depth for a maximum value of $\tau_{\max }$ during the contact period with different asperity conditions. When the gear surface is smooth, the maximum risk of fatigue is approximately 0.8 , which appears at a depth of $0.1 \mathrm{~mm}$. The maximum risk of fatigue is approximately 1.0, 1.2 , and 1.4 when the RMS of the surface roughness is $0.2,0.3$, and $0.4 \mu \mathrm{m}$, respectively. As the RMS increases to $0.5 \mu \mathrm{m}$, the maximum value of the fatigue risk reaches approximately 1.6, and its occurrence location is $0.01 b_{\mathrm{H}}(0.0086 \mathrm{~mm}$ in this work), which is very close to the surface.

Moreover, the range of the influence of the surface roughness is close to the surface. As it can be observed in Fig. 14, the risk of fatigue is highly affected by the surface roughness within a small range. When the RMS is $0.5 \mu \mathrm{m}$, the range of obvious influence is approximately $0.05 \mathrm{~mm}$ from the surface. Although discrepancies in the risk of fatigue could be found on a deeper location compared with a smooth surface, the effect can be ignored when describing a gear contact fatigue as the maximum risk of fatigue occurs at a very shallow location below the gear tooth surface, which is the area dominated by gear contact fatigue modes such as micropitting.

The maximum fatigue failure risk appears at a depth of approximately $0.01 b_{\mathrm{H}}$, which is more than twice the value of that at the surface. This is mainly attributed to the interaction of the peaks of the
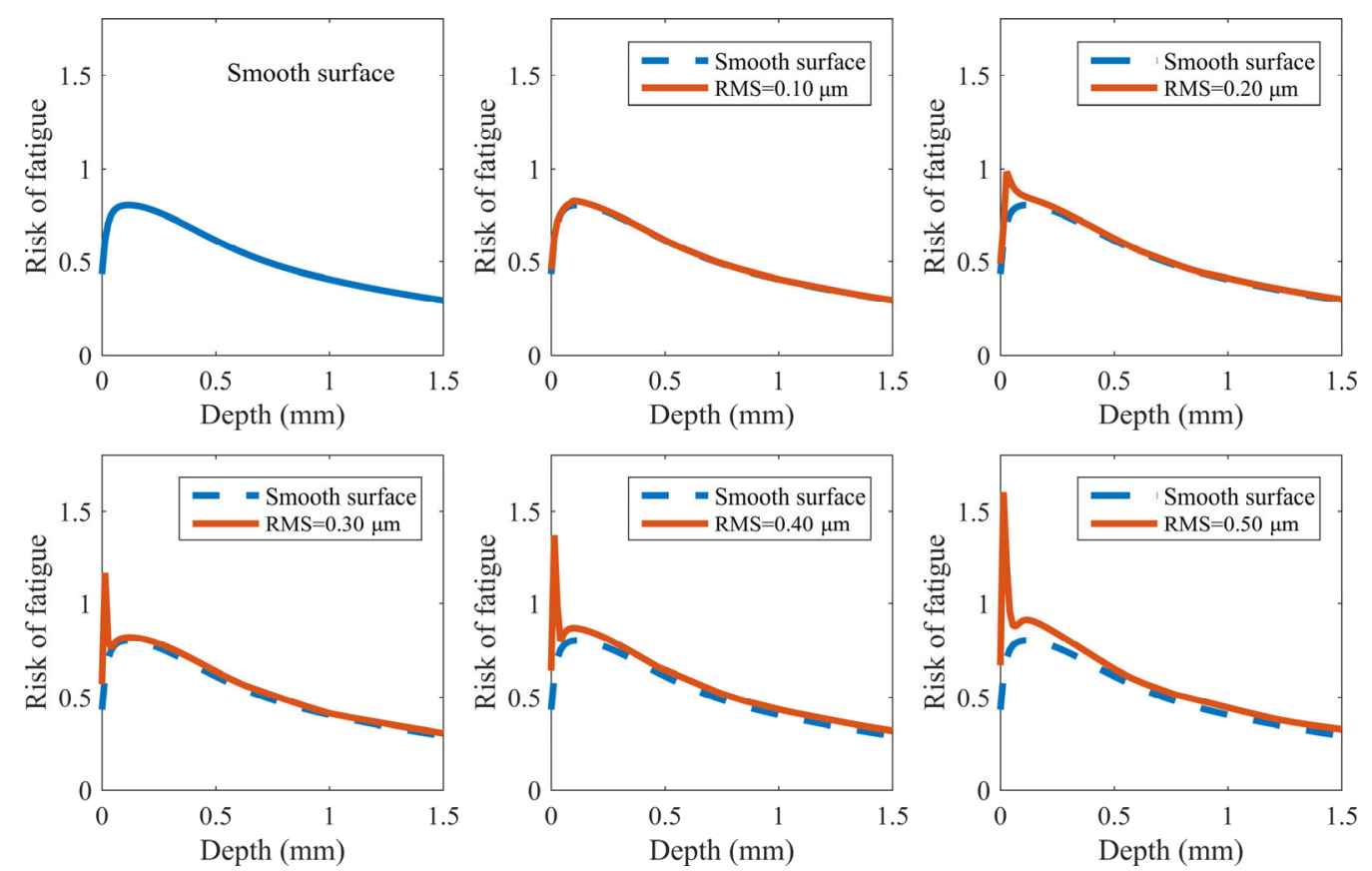

Fig. 13 Contact fatigue risk $R$ along the depth with different surface roughness RMS. 

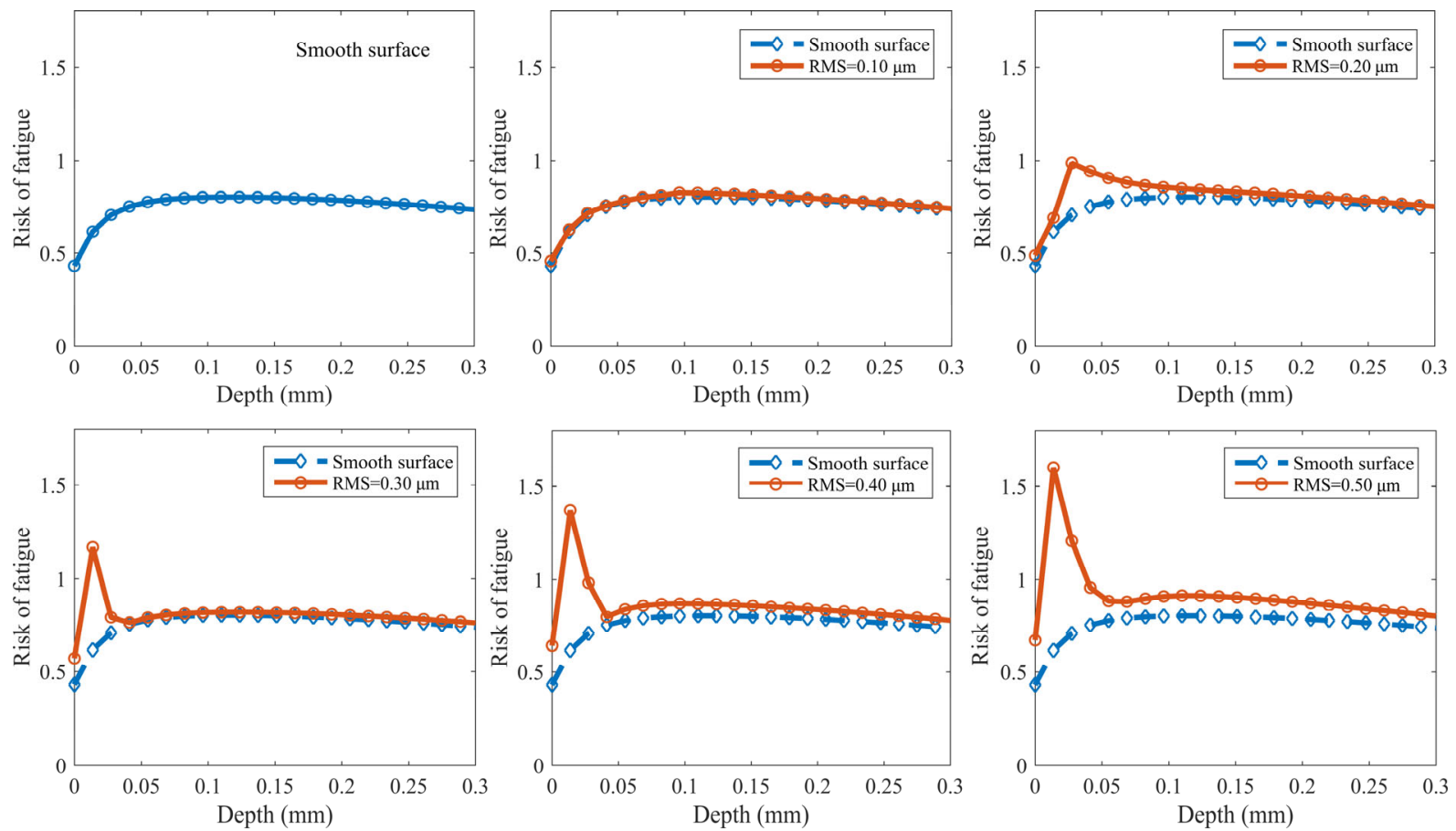

Fig. 14 Contact fatigue risk $R$ along the depth with different surface roughness RMS (partial enlarged).

roughness being considered as an extremely small contact area which is subjected to the Hertzian contact theory. Consequently, the maximum fatigue risk occurs near the surface rather than in the surface in spite of the effect of surface roughness.

Consistent results are displayed in Fig. 15 in which 26 groups of RMS of surface roughness are chosen from 0 to $0.5 \mu \mathrm{m}$ in order to investigate the effect of the surface roughness on the risk of fatigue and to generate the failure risk map. The highest value of

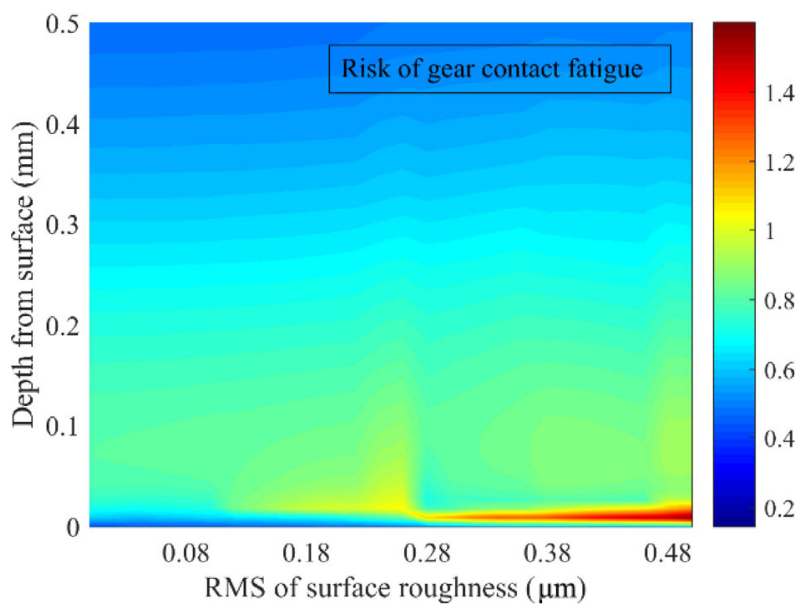

Fig. 15 Fatigue risk map as a function of the roughness RMS value and the depth. the risk of contact fatigue is approximately 1.6 when the RMS is $0.5 \mu \mathrm{m}$. More specifically, the maximum fatigue risk appears at a closer position to the surface and its value exceeds 1.0 when the roughness RMS increases to $0.28 \mu \mathrm{m}$. The maximum risk increases significantly, but the influence of the surface roughness remain within a small range which is fairly close to the gear surface. Consequently, the micropitting is more likely to occur as the RMS value increases during the gear contact process.

\section{Conclusions}

Herein, a numerical model was proposed to study the effect of the gear tooth surface roughness on the contact fatigue behavior of a carburized wind turbine gear pair under lubrication condition. The variations of the hardness and the residual stress were both incorporated in the numerical model. The modified Dang Van diagram and the risk of contact fatigue at critical material points were performed for different roughness cases. The main conclusions are summarized as follows:

(1) No contact fatigue failure is expected to appear with the smooth surface assumption. When the 
compressive residual stress is considered, a decrease of the maximum shear stress at the subsurface can be observed. The location of the maximum is found near the surface, increasing the failure risk near the surface. However, the change of the peak value of the maximum shear stress cannot be observed clearly. The compressive residual stress is beneficial to the resistant ability of the gear contact fatigue failures which occur at the subsurface.

(2) The effect of the surface roughness on the variations of the load path data is more important as the value of RMS increases. More important variations of $\sigma_{\mathrm{H}}$ at the surface are observed because of the greater fluctuations of the pressure distribution caused by the increasing surface roughness, and all investigated load path data at the depth of $0.01 b_{\mathrm{H}}$ are above the modified Dang Van limit. The influence of the surface roughness on the stress distributions sharply decreases as the position becomes deeper.

(3) The increase of the surface roughness RMS increases the maximum risk of fatigue significantly, which occurs in a shallow range. As the roughness RMS increases to $0.5 \mu \mathrm{m}$, the effect of the roughness RMS on the failure risk becomes limited within a depth of $0.05 \mathrm{~mm}$. Therefore, the possibility of the appearance of the micropitting increases during the gear meshing period.

Moreover, fatigue experiments based on the gear samples or other equivalent components will be conducted in future work to determine several important materials and tribological parameters. Subsequently, the current numerical results could be modified and verified based on the experimental data.

\section{Acknowledgements}

The work was supported by the National Natural Science Foundation of China (Nos. U1864210, 51775060, and 51705043) and Chongqing Research Program on Technology Innovation and Application Demonstration (No. cstc2018jszx-cyzdX0053).

Open Access This article is licensed under a Creative Commons Attribution 4.0 International License, which permits use, sharing, adaptation, distribution and reproduction in any medium or format, as long as you give appropriate credit to the original author(s) and the source, provide a link to the Creative Commons licence, and indicate if changes were made.

The images or other third party material in this article are included in the article's Creative Commons licence, unless indicated otherwise in a credit line to the material. If material is not included in the article's Creative Commons licence and your intended use is not permitted by statutory regulation or exceeds the permitted use, you will need to obtain permission directly from the copyright holder.

To view a copy of this licence, visit http://creativecommons.org/licenses/by/4.0/.

\section{References}

[1] Sugianto A, Narazaki M, Kogawara M, Shirayori A, Kim S Y, Kubota S. Numerical simulation and experimental verification of carburizing-quenching process of $\mathrm{SCr} 420 \mathrm{H}$ steel helical gear. J Mater Process Technol 209(7): 3597-3609 (2009)

[2] Boniardi M, D’Errico F, Tagliabue C. Influence of carburizing and nitriding on failure of gears - A case study. Eng Fail Anal 13(3): 312-339 (2006)

[3] Liu H J, Liu H L, Zhu C C, Wei P T, Tang J Y. Tribological behavior of coated spur gear pairs with tooth surface roughness. Friction 7(2): 117-128 (2019)

[4] Ma R, Chen Y S, Cao Q J. Research on dynamics and fault mechanism of spur gear pair with spalling defect. J Sound Vib 331(9): 2097-2109 (2012)

[5] Evans H P, Snidle R W, Sharif K J, Shaw B A, Zhang J. Analysis of micro-elastohydrodynamic lubrication and prediction of surface fatigue damage in micropitting tests on helical gears. J Tribol 135(1): 011501 (2013)

[6] Mackaldener M, Olsson M. Interior fatigue fracture of gear teeth. Fatigue Fract Eng Mater Struct 23(4): 283-292 (2000)

[7] $\mathrm{Pu} \mathrm{W}$, Wang J X, Zhu D. Friction and flash temperature prediction of mixed lubrication in elliptical contacts with arbitrary velocity vector. Tribol Int 99: 38-46 (2016)

[8] Zhou Y, Zhu C C, Liu H J, Song C S, Li Z F. A numerical study on the contact fatigue life of a coated gear pair under EHL. Ind Lubr Tribol 70(1): 23-32 (2018)

[9] Yang P R, Qu S Y, Chang Q Y, Guo F. On the theory of thermal elastohydrodynamic lubrication at high slide-roll ratios-line contact solution. J Tribol 123(1): 137-144 (2001)

[10] Qiao H, Evans H, Snidle R W. Comparison of fatigue model results for rough surface elastohydrodynamic lubrication. Proc Inst Mech Eng, Part J J Eng Tribol 222(3): 381-393 (2008)

[11] Liu H J, Zhu C C, Sun Z D, Song C S. Starved lubrication of a spur gear pair. Tribol Int 94: 52-60 (2016)

[12] Pu W, Zhu D, Wang J X, Wang Q J. Rolling-sliding contact 
fatigue of surfaces with sinusoidal roughness. Int J Fatigue 90: 57-68 (2016)

[13] Yan X L, Wang X L, Zhang Y Y. A parametric study on fatigue life for mixed elastohydrodynamic lubrication point contacts. J Tribol 135(4): 041501 (2013)

[14] Zhu D. Effect of surface roughness on mixed EHD lubrication characteristics. Tribol Trans 46(1): 44-48 (2003)

[15] Zhou W, Tang J Y, He Y F, Liao D R. Associated rules between microstructure characterization parameters and contact characteristic parameters of two cylinders. J Central South Univ 22(11): 4228-4234 (2015)

[16] Sheng L, Kahraman A. A physics-based model to predict micro-pitting lives of lubricated point contacts. Int J Fatigue 47: 205-215 (2013)

[17] Cardoso N F R, Martins R C, Seabra J H O, Igartua A, Rodríguez J C, Luther R. Micropitting performance of nitrided steel gears lubricated with mineral and ester oils. Tribol Int 42(1): 77-87 (2009)

[18] Sadeghi F, Jalalahmadi B, Slack T S, Raje N, Arakere N K. A review of rolling contact fatigue. J Tribol 131(4): 041403 (2009)

[19] Schwenk M, Hoffmeister J, Hermes J. Hardness prediction after case hardening and tempering gears as first step for a local load carrying capacity concept. Forsch Ingenieurwes 81(2-3): 233-243 (2017)

[20] Walvekar A A, Sadeghi F. Rolling contact fatigue of case carburized steels. Int J Fatigue 95: 264-281 (2017)

[21] Rudenko S P, Val'ko A L. Contact fatigue resistance of carburized gears from chromium-nickel steels. Metal Sci Heat Treat 59(1-2): 60-64 (2017)

[22] Lv Y, Lei L Q, Sun L N. Effect of microshot peened treatment on the fatigue behavior of laser-melted $\mathrm{W}_{6} \mathrm{Mo}_{5} \mathrm{Cr}_{4} \mathrm{~V}_{2}$ steel gear. Int J Fatigue 98: 121-130 (2017)

[23] Inoue K, Kato M. Increasing surface hardness and residual stress results in the enhancement of strength of carburized gear teeth. In 29th Joint Propulsion Conference and Exhibit, Joint Propulsion Conferences, Monterey,USA, 1993: 2294.

[24] MackAldener M, Olsson M. Tooth interior fatigue fracturecomputational and material aspects. Int J Fatigue 23(4): 329-340 (2001)

[25] Brandão J A, Martins R, Seabra J H O, Castro M J D. Surface damage prediction during an FZG gear micropitting test. Proc Inst Mech Eng Part J J Eng Tribol 226(12): 1051-1073 (2012)

[26] Liu H L, Liu H J, Zhu C C, He H F, Wei P T. Evaluation of contact fatigue life of a wind turbine gear pair considering residual stress. J Tribol 140(4): 041102 (2018)

[27] Johnson K L. Contact Mechanics. Cambridge (UK): Cambridge University Press, 1987.

[28] Zhang Y Y, Liu H J, Zhu C C, Liu M Y, Song C S. Oil film stiffness and damping in an elastohydrodynamic lubrication line contact-vibration. J Mech Sci Technol 30(7): 30313039 (2016)

[29] Liu H J, Mao K, Zhu C C, Chen S Y, Xu X Y, Liu M Y. Spur gear lubrication analysis with dynamic loads. Tribol Trans 56(1): 41-48 (2013)

[30] Wang Z J, Wang W Z, Wang H, Hu Y Z. Stress analysis on layered materials in point elastohydrodynamic-lubricated contacts. Tribol Lett 35(3): 229-244 (2009)

[31] Peiran Y, Wen S Z. A generalized Reynolds equation for non-Newtonian thermal elastohydrodynamic lubrication. $J$ Tribol, 112(4): 631-636 (1990)

[32] Dowson D, Higginson G R. Elasto-hydrodynamic lubrication: the fundamentals of roller and gear lubrication. Oxford (UK): Pergamon Press, 1966.

[33] Yang P R, Wen S Z. A generalized Reynolds equation for non-Newtonian thermal elastohydrodynamic lubrication. $J$ Tribol 112(4): 631-636 (1990)

[34] Liu S B, Wang Q, Liu G. A versatile method of discrete convolution and FFT (DC-FFT) for contact analyses. Wear 243(1-2): 101-111 (2000)

[35] Li S. Lubrication and contact fatigue models for roller and gear contacts. Ph.D. Thesis. Columbus (USA): The Ohio State University, 2009.

[36] Charkaluk E, Constantinescu A, Maïtournam H, Van D. Revisiting the Dang Van criterion. Procedia Eng 1(1): 143 146 (2009)

[37] Brandão J A, Seabra J H O, Castro J. Surface initiated tooth flank damage: Part I: Numerical model. Wear 268(1-2): $1-12$ (2010)

[38] Ciavarella M, Maitournam H. On the Ekberg, Kabo and Andersson calculation of the Dang Van high cycle fatigue limit for rolling contact fatigue. Fatigue Fract Eng Mater Struct 27(6): 523-526 (2004)

[39] van Lieshout P S, den Besten J H, Kaminski M L. Validation of the corrected Dang Van multiaxial fatigue criterion applied to turret bearings of FPSO offloading buoys. Ships Offshore Struct 12(4): 521-529 (2017)

[40] Desimone H, Bernasconi A, Beretta S. On the application of Dang Van criterion to rolling contact fatigue. Wear 260(4-5): 567-572 (2006)

[41] Cerullo M. Application of Dang Van criterion to rolling contact fatigue in wind turbine roller bearings under elastohydrodynamic lubrication conditions. Proc Inst Mech Eng Part C J Mech Eng Sci 228(12): 2079-2089 (2014)

[42] Agha S R, Liu C R. Experimental study on the performance of superfinish hard turned surfaces in rolling contact. Wear 244(1-2): 52-59 (2000)

[43] Bernasconi A, Davoli P, Filippini M, Foletti S. An integrated approach to rolling contact sub-surface fatigue assessment of railway wheels. Wear 258(7-8): 973-980 (2005)

[44] Beretta S, Foletti S. Propagation of small cracks under RCF: 
A challenge to multiaxial fatigue criteria. In Proceedings of the 4th international conference on Crack Paths, Cassino, Italy, 2012.

[45] Osman T, Velex P. A model for the simulation of the interactions between dynamic tooth loads and contact fatigue in spur gears. Tribol Int 46(1): 84-96 (2012)

[46] Boiadjiev I, Witzig J, Tobie T, Stahl K. Tooth flank fracture-

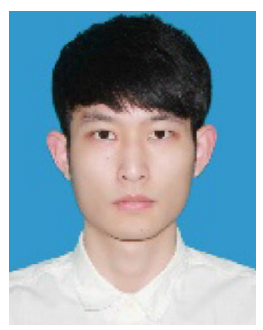

Heli LIU. He has been studying as a master student in State Key Laboratory Mechanical Transmissions (SKLMT), Chongqing University,

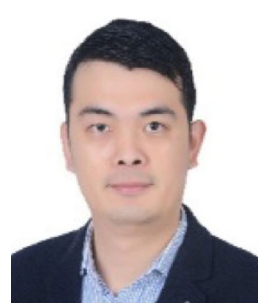

Huaiju LIU. He is currently working as an associate professor in State Key Laboratory of Mechanical Transmissions (SKLMT), Chongqing

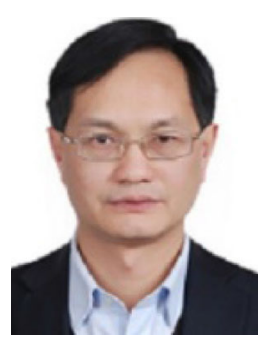

Caichao ZHU. He is a professor in State Key Laboratory of Mechanical Transmissions (SKLMT), Chongqing University, China. He received the

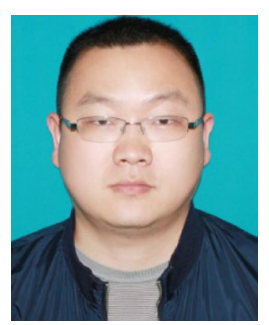

Zhangdong SUN. He is working as a lecturer in Hubei university of Automotive Technology, China. He obtained the Ph.D. degree from

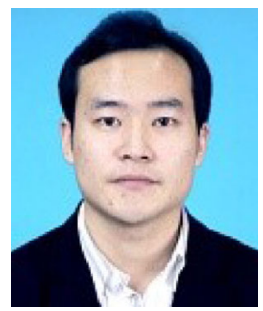

basic principles and calculation model for a sub surface initiated fatigue failure mode of case hardened gears. In International Gear Conference 2014: 26th-28th August 2014, Lyon, France, 2014.

[47] Witzig J. Flankenbruch Eine Grenze der Zahnradtragfähigkeit in der Werkstofftiefe. Ph.D. Thesis. München (Germany) : Technische Universität München, 2012.

China, since 2016. His research interest includes gear contact fatigue failure mechanisms based upon the surface integrity properties.

University, China. He obtained the Ph.D. degree from the University of Warwick, UK, in 2013. His research fields include tribology and fatigue behaviors of mechanical elements.

Ph.D. degree from Chongqing University, China, in 1998. His research is mainly related to the dynamic analysis of transmission systems, including the estimation and control of the vibration and noise.

Chongqing University, China, in 2016. His research basically focuses on friction, vibration, and noise analysis for gear transmission.

in State Key Laboratory Mechanical Transmissions (SKLMT), Chongqing University, China. His research is mainly about the innovative gearbox design. 